\title{
IMPACTOS DE LA PANDEMIA COVID-19 EN EL RENDIMIENTO ACADÉMICO UNIVERSITARIO DURANTE LA TRANSICIÓN A LA EDUCACIÓN VIRTUAL
}

\author{
IMPACTOS DA PANDEMIA COVID-19 NO DESEMPENHO ACADÊMICO \\ UNIVERSITÁRIO DURANTE A TRANSIÇÃO PARA A EDUCAÇÃO VIRTUAL
}

\author{
IMPACTS OF THE COVID-19 PANDEMIC ON UNIVERSITY ACADEMIC \\ PERFORMANCE DURING THE TRANSITION TO VIRTUAL EDUCATION
}

\author{
Herlinda Gervacio Jiménez \\ https://orcid.org/0000-0003-3037-9528 \\ Benjamín Castillo Elías2 ${ }^{2}$ \\ https://orcid.org/0000-0003-1487-5353
}

\begin{abstract}
Resumen
El objetivo del presente estudio fue identificar y analizar los impactos y retos académicos, así como las problemáticas a las que se han enfrentado los estudiantes universitarios de sexto y cuarto semestre de preparatoria, durante la suspensión de actividades educativas presenciales y el traslado a las actividades escolares virtuales, a causa de la actual pandemia del coronavirus Covid19 que provocó recurrir a una educación virtual. Se utilizó una metodología mixta para el proceso de recolección, análisis y vinculación de datos cuantitativos y cualitativos; los datos cuantitativos se recolectaron a través de encuestas diseñadas en Google Forms, mientras que los datos cualitativos se recolectaron por medio de video llamadas grupales e informantes clave. Los resultados mostraron impactos negativos en el rendimiento escolar debido a factores socioeconómicos que enfrentaron y siguen enfrentando los estudiantes y sus familias, afectando su bienestar socioemocional. Dentro de las afectaciones y limitantes predominantes, se observó la condición económica, falta de equipo y dispositivos electrónicos, escaso manejo de plataformas y herramientas virtuales, falta de conexión a internet y un deficiente acompañamiento psicológico durante el confinamiento. Se concluyó que el cierre prolongado de la Universidad ha tenido efectos y repercusiones negativas en distintos aspectos de la vida cotidiana de los estudiantes, un alto grado de vulnerabilidad en las habilidades socioemocionales provocando con ello un deterioro socioemocional y estancamiento académico.
\end{abstract}

Palabras clave: Aprendizaje virtual. Educación formal. Enseñanza-aprendizaje. Rendimiento escolar.

\footnotetext{
${ }^{1}$ Doctora en Ciencias Ambientales. Profesora Investigadora de la Universidad Autónoma de Guerrero, México. Integrante del Cuerpo Académico UAGRO-CA-213-Educación, Ambiente y Sociedad. E-mail: lindagjog@gmail.com

${ }^{2}$ Doctor en Ciencias Ambientales. Profesor Investigador de la Universidad Autónoma de Guerrero, México. Integrante del Cuerpo Académico UAGRO-CA-213-Educación, Ambiente y Sociedad. E-mail: bcastilloelias@gmail.com
}

Como referenciar este artigo: GERVACIO, J. H.; CASTILLO, E. B. Impactos de la pandemia covid-19 en el rendimiento escolar durante la transición a la educación virtual. Revista Pedagógica, v. 23, p. 1-29, 2021. 


\title{
Resumo
}

O objetivo do presente estudo foi identificar e analisar os impactos e desafios acadêmicos, bem como as problemáticas que têm enfrentado os estudantes universitários do sexto e quarto semestre do ensino médio, durante a suspensão das atividades educacionais presenciais e a transferência para as atividades escolares virtuais, devido à atual pandemia de coronavírus Covid19 que ocasionou o uso da educação virtual. Foi utilizada uma metodologia mista para o processo de recolha, análise e ligação de dados quantitativos e qualitativos; Os dados quantitativos foram coletados através de pesquisas feitas no Google Forms, enquanto os dados qualitativos foram coletados por meio de vídeo chamadas em grupo e informantes chave. Os resultados mostraram impactos negativos no rendimento escolar devido a fatores socioeconômicos que enfrentaram e continuam enfrentando os estudantes e suas famílias, afetando seu bem-estar socioemocional. Dentro das afetações e limitações predominantes, observou-se a condição econômica, falta de equipamentos e dispositivos eletrônicos, escasso manejo de plataformas e ferramentas virtuais, falta de ligação à Internet e deficiente acompanhamento psicológico durante o confinamento. Concluiu-se que o encerramento prolongado da Universidade teve efeitos e repercussões negativas em diversos aspectos da vida quotidiana dos estudantes, um elevado grau de vulnerabilidade nas capacidades socioemocionais, provocando uma deterioração socioemocional e estagnação académica.

Palavras-chave: Aprendizagem virtual. Educação formal. Ensino-aprendizagem. Rendimento escolar.

\begin{abstract}
The objective of this study was to identify and analyze the academic impacts and challenges, as well as the problems faced by university students in the sixth and fourth semesters of high school, during the suspension of face-to-face educational activities and the transfer to virtual school activities, due to the current Covid-19 coronavirus pandemic that led to the use of virtual education. A mixed methodology was used for the process of collecting, analyzing, and linking quantitative and qualitative data; quantitative data were collected through surveys designed in Google Forms, while qualitative data were collected through video-based group calls and key informants. The results showed negative impacts on school performance due to socioeconomic factors that students and their families faced and continue to face, affecting their socio-emotional well-being. Among the predominant effects and limitations, the economic condition, lack of electronic equipment and devices, poor management of virtual platforms and tools were observed, lack of internet connection, and poor psychological support during confinement. It was concluded that the prolonged closure of the University has had negative effects and repercussions on different aspects of the daily lives of students, a high degree of vulnerability in socio-emotional skills, thereby causing socio-emotional deterioration and academic stagnation.
\end{abstract}

Keywords: Virtual learning. Formal education. Teaching-learning. School performance.

\section{INTRODUCCIÓN}

El 31 de diciembre de 2019, se informó a la Oficina de la Organización Mundial de Salud (OMS) en China de varios casos de neumonía de etiología de causa desconocida, detectados en la ciudad de Wuhan, provincia de Hubei, China (OMS, 2020), nadie imaginó 
su transcendencia y proporciones globales, el 2020 llegaba con una nueva realidad, una pandemia que desequilibraría el ritmo de vida del ser humano. Se trata de una pandemia por un virus denominado SARS-CoV-2 que produce la enfermedad Covid-19 (OMS, 2020), con un alto índice de contagio, lo que ha producido el cese prácticamente de todas las actividades económicas, culturales y educativas; así como el cierre total de las escuelas a nivel global. Esta pandemia tomó de sorpresa a los gobiernos y habitantes del mundo, no se pudo prever la magnitud y alcance de la enfermedad causada por este virus, tampoco fue posible dimensionar sus consecuencias e impactos sociales, ambientales, económicos y políticos que produciría.

El virus Covid-19 se convirtió en unos meses en pandemia con efectos devastadores para todos los integrantes de la sociedad (Yl et al., 2020), de un momento a otro, las escuelas y universidades de todo el mundo cerraron sus puertas afectando a 1, 570 millones de estudiantes en 191 países (UNESCO-IESALC, 2020). La incertidumbre y sorpresa por lo rápido que se ha alterado la vida de prácticamente todos los habitantes del planeta, ha creado una situación inédita para todas las organizaciones, incluyendo las instituciones educativas, quienes se han visto obligadas a suspender las actividades académicas, en una transición abrupta y obligada a la educación a distancia mediada por la tecnología (GERVACIO y CASTILLO, 2020).

Los estudiantes, se enfrentan a los efectos del Covid-19 en la vida cotidiana, como el cierre de escuelas, empresas y lugares públicos, cambios en las rutinas de trabajo y la organización familiar (CERVANTES, et al., 2020); además de enfrentarse al estrés y al aislamiento que conlleva sentimientos de impotencia y abandono (RODRíGUEZ et al., 2017; ORNELL et al., 2020), los estudiantes y sus familias han enfrentado impactos financieros derivado de la pérdida total o parcial de sus empleos. Al respecto Gervacio y Castillo (2020); Gudi y Tiwari (2020) han analizado los efectos del Covid-19 en la vida cotidiana, considerando la importancia en el cuidado de la salud, empleo, educación, alimentación y los impactos que conlleva la falta de éstos.

La suspensión obligatoria de las clases en todos los niveles educativos, con el confinamiento en casa de estudiantes y profesores, ha creado una red de efectos múltiples en todos los actores del proceso educativo (SÁNCHEZ et al., 2020). Por un lado, las escuelas y universidades han tomado una serie de medidas para acatar las indicaciones y 
recomendaciones de las autoridades educativas locales de sus respectivos gobiernos, por otro lado, instituciones internacionales como la Organización de las Naciones Unidas para la Educación la Ciencia y la Cultura (UNESCO), el Instituto Internacional para la Educación Superior en América Latina y el Caribe (IESALC), el Fondo de las Naciones Unidas para la Infancia (United Nations International Children's Emergency Fund: UNICEF) y la OMS, han sido clave ante la tragedia global, proponiendo directrices, lineamientos y recomendaciones para dar continuidad en lo posible a los procesos educativos y de salud (OMS, 2020; UNESCO-IESALC, 2020; UNICEF, 2020).

La intervención de la UNESCO y otras instituciones internacionales, han sido clave ante la tragedia global, con la finalidad de dar seguimiento a los acontecimientos en materia de educación, éstas, han instruido a los gobiernos e instituciones educativas sobre la importancia de la planificación de medidas adecuadas que protejan la salud de la ciudadanía, evitando conculcar el derecho a la educación en todos los niveles educativos (UNESCO, 2020); de igual manera, han exhortado a los gobiernos del mundo a poner en práctica medidas que favorezcan a los estudiantes para que sigan aprendiendo a pesar del cierre temporal de las instituciones educativas (UNESCO-IESALC, 2020).

Al mismo tiempo, los países de América Latina y el Caribe han lanzado iniciativas de enseñanza remota de emergencia para proporcionar soluciones de corto plazo y mantener cierta continuidad en los procesos de enseñanza aprendizaje (HODGES et al., 2020). Al igual que en distintas instituciones educativas del mundo, México ha enfrentado estos desafíos con una capacidad de respuesta limitada, tal como demuestran los distintos diagnósticos sobre los Sistemas de Información y Gestión Educativa, la capacidad de muchos centros educativos de la región sobre la planificación y gestión del sistema educativo, ya era limitada antes de la crisis, por lo que hacerlo remotamente y durante la crisis sanitaria, ha sido complicado y complejo (ARIAS et al., 2019).

El gobierno mexicano a través de la Secretaria de Educación Pública, por decreto publicado el 23 de marzo del 2020 en el Diario Oficial de la Federación (DOF, 2020), ordenó el cierre total de las escuelas del país, con la finalidad de no interrumpir el aprendizaje de miles de estudiantes mexicanos, dando continuidad a la enseñanza-aprendizaje a través de medios virtuales. Mover el aprendizaje de las aulas a los hogares a gran escala y de forma acelerada, ha presentado enormes desafíos, tanto humanos como técnicos (SEP, 2020). 
En este contexto y ante la emergencia sanitaria, la Universidad Autónoma de Guerrero (UAGro), a través de la rectoría, ha diseñado una serie de acciones estratégicas en apoyo a la comunidad local y sobre todo, para cuidar y proteger la salud e integridad de los universitarios. Dentro de las acciones emergentes fue la continuidad de las actividades académicas educativas a través de plataformas virtuales, se diseñaron cursos para el manejo de la Plataforma Google Classroom; dentro de las estrategias implementadas fue la capacitación a docentes y estudiantes a través de esta plataforma, a los docentes se les instruyó para el correcto manejo de las herramientas digitales, así como el diseño metodológico para continuar las actividades didáctico-pedagógicas; se capacitó a los estudiantes para el adecuado uso e incorporación a las actividades académicas a través de la Plataforma Google Classroom. En medio del caos y la incertidumbre, el 15 de julio del 2020 se dio por concluido el semestre enero-julio de forma virtual, dando continuidad al semestre agosto 2020-enero 2021 con el mismo proceso de enseñanza virtual.

\section{METOdOLOGÍA}

\section{1. Área de estudio}

El presente estudio se realizó en la escuela preparatoria No. 2 del Nivel Medio Superior de la Universidad Autónoma de Guerrero, ubicada en la Ciudad de Acapulco, Guerrero, México.

\subsection{Diseño metodológico}

Para llevar a cabo la presente investigación se utilizó una metodología mixta, la cual implicó la recolección, análisis y vinculación de datos cuantitativos y cualitativos (TAYLOR y BOGDAN, 2000; FERNÁNDEZ y DÍAZ, 2002; ALZATE et al., 2008; MONJE, 2011; GÓMEZ, 2012; HERNÁNDEZ-SAMPIERI et al., 2018).

Una vez concluido el ciclo escolar febrero-julio del 2020 en la modalidad virtual, se consideró pertinente conocer de qué manera ha impactado a los estudiantes bajo estudio 
la actual crisis sanitaria del Covid-19 en la vida cotidiana de estudiantes de la escuela preparatoria No. 2 del turno vespertino de la UAGro.

De acuerdo con Pita (1996); Pértegas y Pita (2002) se determinó el tamaño de muestra de 102 de una población total de 178 estudiantes matriculados para el sexto y cuarto semestre, considerando que se trata de una población finita, aplicando la fórmula:

$$
n=\frac{N^{*} Z_{z}^{2} p^{*} q}{d^{2} *(N-1)+Z_{z}^{2} p^{*} q}
$$

Donde:

$>n=$ Tamaño de muestra a elegir

$>\mathrm{N}=$ Total de la población

$>Z_{a}^{2}=1.96^{2}$ (si la seguridad es del 95\%)

$>\mathrm{p}=$ proporción esperada (en este caso $5 \%=0.05$ )

$>\mathrm{q}=1-\mathrm{p}$ (en este caso $1-0.05=0.95$ )

$>d=$ precisión (en este caso deseamos un 3\%).

Lo anterior se considera una muestra representativa, ya que el resultado del cálculo mediante la fórmula proporcionó un total de 95 personas, lo que es considerada como una muestra representativa; en este caso, participaron voluntariamente 102 estudiantes.

\subsubsection{Metodología cualitativa}

La metodología empleada en este apartado, ha permitido realizar un análisis exploratorio, inductivo y descriptivo (MONJE, 2011), por medio de la técnica de acción participante (TAYLOR y BOGDAN, 2000; GÓMEZ, 2012; HERNÁNDEZ-SAMPIERI et al., 2018), durante el semestre febrero-julio del 2020, se programaron talleres virtuales como estrategia de acompañamiento, con una duración de una hora por semana, con un total de 4 sesiones por mes, esta intervención se llevó a cabo en los meses de febrero, marzo, abril y mayo, con un total de 16 horas, con las siguientes temáticas:

Vivencia personal durante la contingencia sanitaria y el confinamiento.

$>$ Mis sentimientos, el confinamiento y la contingencia.

$>$ Vivir mi nueva realidad. 
A través de estos talleres virtuales, se permitió recolectar datos e inferencias cualitativas a través de una bitácora digital de registro como instrumento cualitativo, este instrumento cumplió dos funciones pedagógicas paralelamente, ser facilitador tanto de la enseñanza como del aprendizaje y valorar elementos conceptuales, cognitivos, emocionales y éticos de los estudiantes (ALZATE et al., 2008).

Para el análisis, fue necesario clasificar semánticamente las respuestas, posteriormente se agruparon por categorías, lo que permitió identificar otras problemáticas a las que se han enfrentado los estudiantes y que no fueron mencionadas en las reuniones virtuales. Esta técnica propia de la metodología cualitativa, citadas por Taylor y Bogdan (2000); Gómez (2012), involucran la interacción social entre el investigador y los informantes clave dentro de un escenario social, ambiente o contexto; durante esta investigación se recolectaron datos de modo sistemático y no intrusito tal como lo recomiendan HERNÁNDEZ-SAMPIERI et al. (2018). De esta manera, esta técnica ha permitido obtener datos amplios, profundos y detallados sobre el proceso que han vivido los estudiantes durante la contingencia sanitaria a partir de la suspensión de las clases presenciales y el traslado a las clases virtuales.

\subsubsection{Metodología cuantitativa}

Se utilizó la encuesta como instrumento de recolección de datos categorizado por opción múltiple (GÓMEZ, 2012; HERNÁNDEZ-SAMPIERI et al., 2018), los encuestados pudieron seleccionar más de una alternativa de respuesta, ésta fue elaborada por medio de la aplicación Google Forms diseñada para la creación de encuestas y formularios, la encuesta fue enviada simultáneamente a los estudiantes a través del correo institucional con un breve mensaje de invitación para participar en el presente estudio de forma voluntaria, a través de un link que lleva directamente al instrumento en la plataforma de Google Classroom; esta herramienta permitió capturar, monitorear y organizar las respuestas en tiempo real.

Para el análisis estadístico, los resultados de Google Forms se exportaron a Google Sheets, para realizar la selección, traducción, transposición y codificación de los datos y 
generar las estadísticas descriptivas y los gráficos con los resultados (MENDIOLA et al., 2020).

\section{RESULTADOS}

\subsection{Análisis cuantitativo}

El primer análisis se centró en los resultados obtenidos a través de encuestas por medio de Google Forms, éstos se exportaron a Google Sheets para realizar la selección, traducción, transposición y codificación de los datos, y generar las estadísticas descriptivas y las gráficas de los resultados.

Los resultados obtenidos sobre el nivel de esfuerzos en tus cursos, se preguntó a los estudiantes sobre el nivel de esfuerzo que habían puesto en sus cursos virtuales, el $35 \%$ consideró haber realizado un esfuerzo muy bueno, mientras que para el 26 \% fue satisfactorio, un 25 \% consideró un esfuerzo medio, para el $13 \%$ lo consideró excelente, solo un $1 \%$ deficiente.

Con respecto al nivel de dificultad que han tenido para realizar sus actividades escolares, un 15 \% consideró que tuvieron un elevado nivel de dificultad considerando su desempeño deficiente, el 59 \% mencionó que fue regular el nivel de dificultad, considerada para ellos como una dificultad media; para un 10 \% consideró su desempeño satisfactorio con un nivel de dificultad regular, mientras que para un $11 \%$ el nivel de dificultad fue bajo, por lo que consideraron un desempeño muy bueno, y solo el 5 \% consideró que no tuvieron dificultad para realizar sus actividades escolares, por lo que consideraron su desempeño excelente.

Con respecto al nivel de aprendizaje obtenido en los cursos en línea, al respecto, el 10 \% consideró su nivel de aprendizaje deficiente; un 30 \% consideró su nivel de aprendizaje medio; para el 29 \% fue satisfactorio, mientras que un $19 \%$ consideró su nivel de aprendizaje muy bueno, el 12 \% consideró excelente su nivel de aprendizaje.

Sobre la facilidad para el acceso a clases virtuales, un $10 \%$ consideró que fue deficiente, el 33 \% consideró que fue fácil el acceso a sus clases virtuales, para el $22 \%$ el 
acceso a las clases virtuales fue satisfactorio, el 24 \% lo consideró muy bueno y sólo el 11 \% consideró que el acceso a las clases virtuales fue excelente.

En la figura 1 se observa el comportamiento de los resultados antes mencionados.

Figura 1 - Nivel de esfuerzo en los cursos

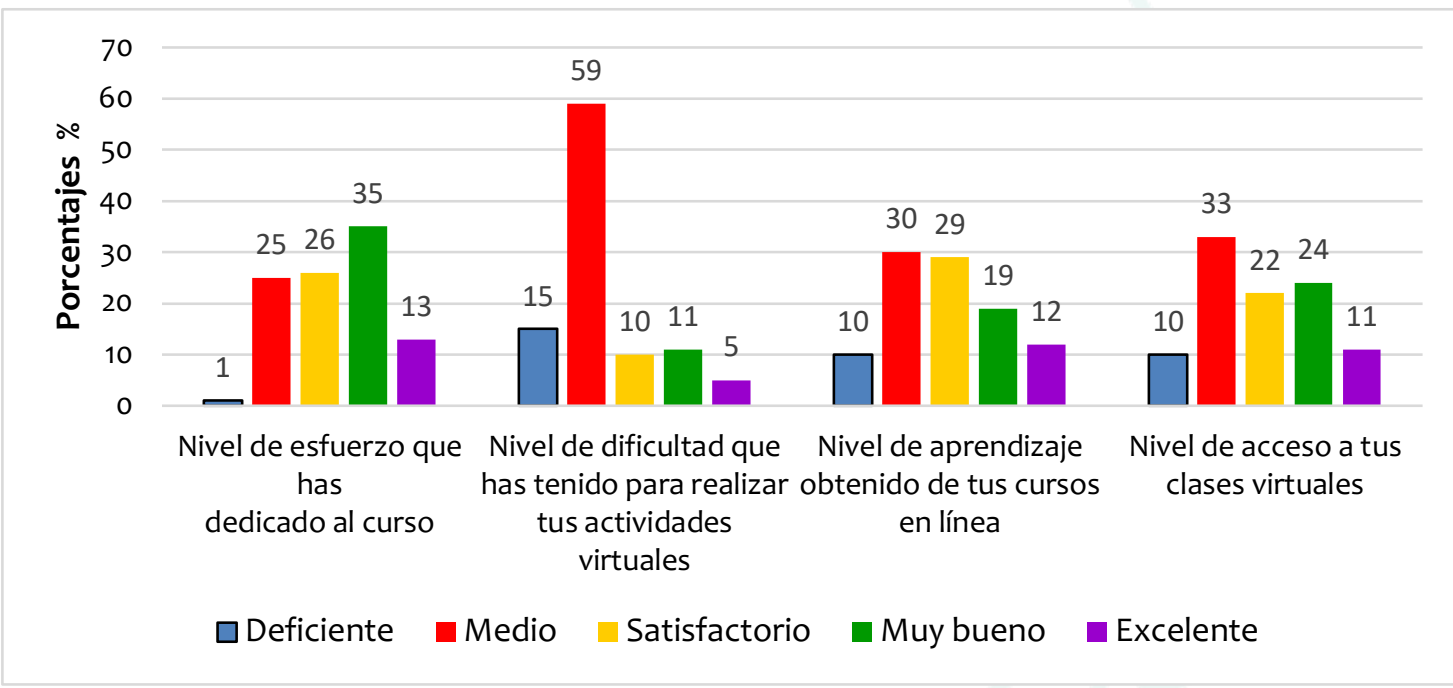

Fuente: Elaboración propia

Acerca de los conocimientos adquiridos en las asignaturas al inicio del curso, se preguntó a los estudiantes el nivel de habilidad y conocimiento al inicio del su curso de manera virtual, su nivel de habilidad y conocimiento al inicio del curso fue de deficiente (8\%) a medio ( $41 \%)$, mientras que para el $21 \%$ se consideró satisfecho en su nivel de habilidad, para un 25 \% lo consideró muy bueno y un 5 \% consideró excelente su nivel de habilidad y conocimiento.

Los resultados obtenidos sobre el nivel de habilidad y conocimiento al final del su curso, un 35 \% consideró que los resultados al finalizar el curso fueron de deficientes a medio, un 29 \% lo consideró satisfactorio, mientras que para un 20 \% fue considerado muy bueno y para un $16 \%$ lo consideró excelente.

En esta variable de antes y después del curso, se observa un ligero cambio ya que al inicio un $49 \%$ consideraban su nivel de habilidad deficiente a medio en contraste con los resultados obtenidos al final del curso con un 35\% que consideró su nivel de habilidad y conocimiento de deficiente a medio, observándose un 14\% de diferencia entre el inicio y al final del curso, observándose un incipiente cambio en los resultados sobre el nivel de habilidad y conocimiento al inicio y final del semestre. 
Con relación al nivel de habilidades y conocimientos adquiridos, el 36 \% consideró que su nivel de habilidades fue de deficiente a medio, el 30 \% lo consideró su nivel de habilidades satisfactorio, un 24 \% lo consideró su nivel de habilidades muy bueno, para un $10 \%$ fue considerado excelente.

Referente a la pregunta sobre la contribución del curso para mejorar las habilidades o conocimientos, el 10 \% refirió que fue una contribución deficiente, el 31 \% lo consideró una contribución media con una escala regular, mientras que el $21 \%$ consideró un curso satisfactorio, para un 22 \% fue muy bueno y el 16 \% refirió que fue un curso excelente (Figura 2).

Figura 2 - Conocimientos adquiridos en todas las asignaturas

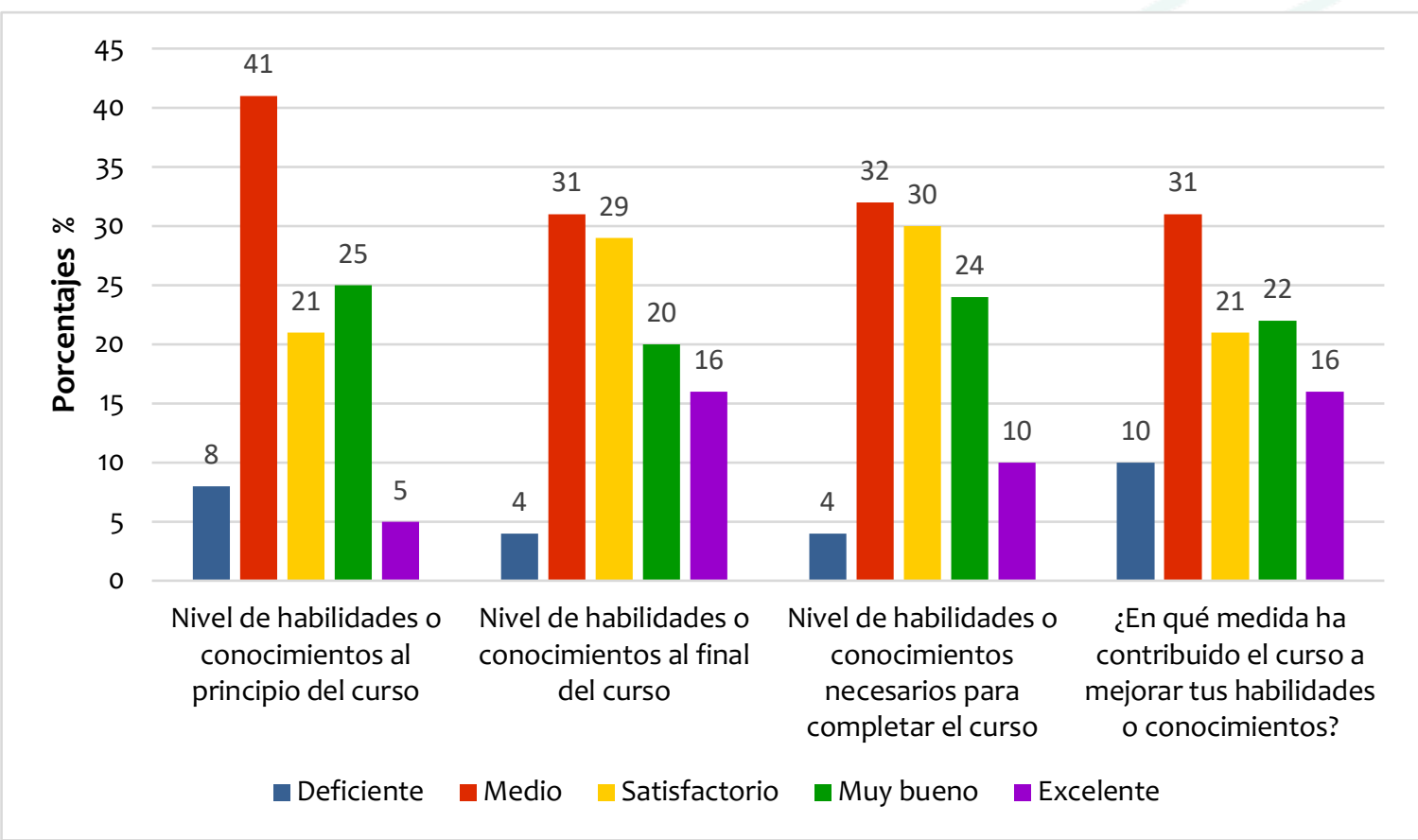

Fuente: Elaboración propia

Con respecto a las habilidades y dedicación de tus profesores, se les preguntó sobre el nivel de habilidades y conocimientos que mostraron los docentes que impartieron los cursos, se solicitó que evaluaran el desempeño de su profesor al finalizar el semestre, un $13 \%$ estuvieron totalmente de acuerdo sobre las habilidades y desempeño de sus docentes, un $35 \%$ estuvieron de acuerdo, mientras que un $34 \%$ permaneció neutral, en este caso, los estudiantes prefirieron no opinar nada sobre las habilidades y el desempeño de sus docentes, aun cuando se les explicó que la encuesta fue anónima y se realizó una vez que los profesores habían entregado evaluaciones, un $10 \%$ estuvo en desacuerdo, 
considerando que los docentes no poseen las habilidades tecnológicas necesarias y un $8 \%$ dijo estar en completo desacuerdo sobre las habilidades que poseen sus docentes facilitadores.

En cuanto al nivel de estímulo-motivación que ejercieron los profesores durante sus clases virtuales, un 15 \% estuvieron totalmente de acuerdo sobre el nivel de estímulo que han ejercido los docentes, un 40 \% estuvieron de acuerdo sobre la motivación ejercida por sus profesores, el 27 \% se mantuvo neutral, de igual manera, prefirieron no dar su opinión; el 14 \% estuvo en desacuerdo, el 4 \% manifestó estar muy en desacuerdo.

En cuanto al aprovechamiento académico durante el semestre, un $24 \%$ estuvo totalmente de acuerdo que el curso fue aprovechado, mientras que el $31 \%$ dijo estar de acuerdo, un $28 \%$ se mantuvieron neutrales, prefirieron no opinar al respecto, un $14 \%$ dijo estar en desacuerdo sobre su aprovechamiento académico durante el semestre y un $3 \%$ dijo estar muy en desacuerdo sobre su aprovechamiento académico.

La disposición y atención de los docentes hacia los estudiantes, los estudiantes se sintieron apoyados en todo momento, un $6 \%$ de estudiantes dijeron estar muy en desacuerdo sobre la atención y apoyo, el 12 \% estuvieron en desacuerdo, en tanto que el 32 \% se mantuvo neutral, prefierieron no emitir su opinión, mientras que el 26 \% estuvieron de acuerdo y el 24 \% dijeron estar muy de acuerdo en cuanto a la disposición y apoyo.

Con respecto a la realimentación y puntualidad en calificaciones y notas de los trabajos en plataforma, el 8 \% dijo estar muy en desacuerdo y un $12 \%$ en desacuerdo sobre la realimentación y puntualidad de entrega de calificaciones, el 25 \% se mantuvo neutral prefiriendo no ofrecer su opinión, un 29 \% dijeron estar de acuerdo, mientras que un $26 \%$ dijo estar totalmente de acuerdo (Figura 3). 
Figura 3 - Habilidades y dedicación de los profesores

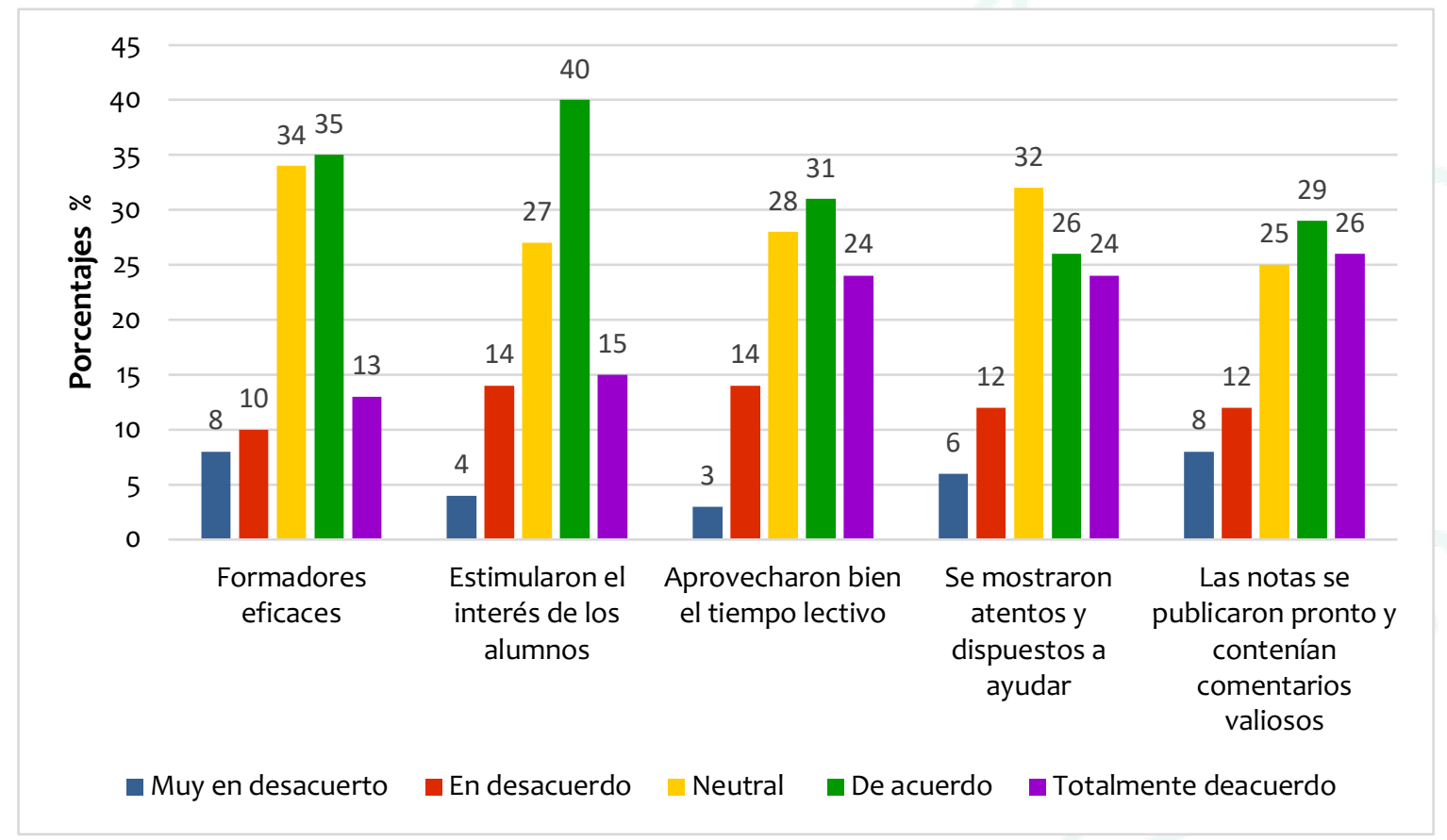

Fuente: Elaboración propia

En cuanto al contenido de las asignaturas, claridad en los objetivos, se preguntó si los objetivos fueron claros; un $15 \%$ estuvo totalmente de acuerdo y un $39 \%$ de acuerdo sobre la claridad de los objetivos de las asignaturas, mientras que el $29 \%$ se mantuvo neutral con respecto a esta pregunta, mientras que un $4 \%$ dijo estar en desacuerdo y $13 \%$ estuvo totalmente en desacuerdo sobre la claridad de los objetivos de la asignatura.

En cuanto a la planificación de contenidos, se preguntó a los estudiantes si los contenidos estaban planificados y organizados por temáticas; el $37 \%$ estuvo de acuerdo y $19 \%$ totalmente de acuerdo, un $24 \%$ se mantuvo neutral, mientras que el $12 \%$ dijeron estar en desacuerdo y un 8 \% dijo estar muy en desacuerdo sobre la planificación de contenidos.

Con respecto a la adecuada y razonable carga de trabajo, se preguntó si las actividades y trabajos de investigación fueron razonables y adecuadas, el 14 \% estuvo totalmente de acuerdo con las actividades solicitadas por los docentes, un $25 \%$ estuvo de acuerdo, un $29 \%$ se mantuvo neutral y no respondió la pregunta, el $22 \%$ estuvieron en desacuerdo y el $10 \%$ muy en desacuerdo sobre la carga de trabajo para los estudiantes.

Con la finalidad de tener un contraste sobre la misma pregunta, en este caso excesiva carga de trabajo, un $21 \%$ estuvo totalmente de acuerdo y el $24 \%$ de acuerdo con la excesiva carga de tareas solicitadas por parte de los docentes facilitadores, un 33 se 
mantuvo neutral, prefirió no contestar la pregunta, un $10 \%$ en desacuerdo y un $12 \%$ dijo estar completamente en desacuerdo (Figura 4).

Figura 4 - Contenido de las asignaturas

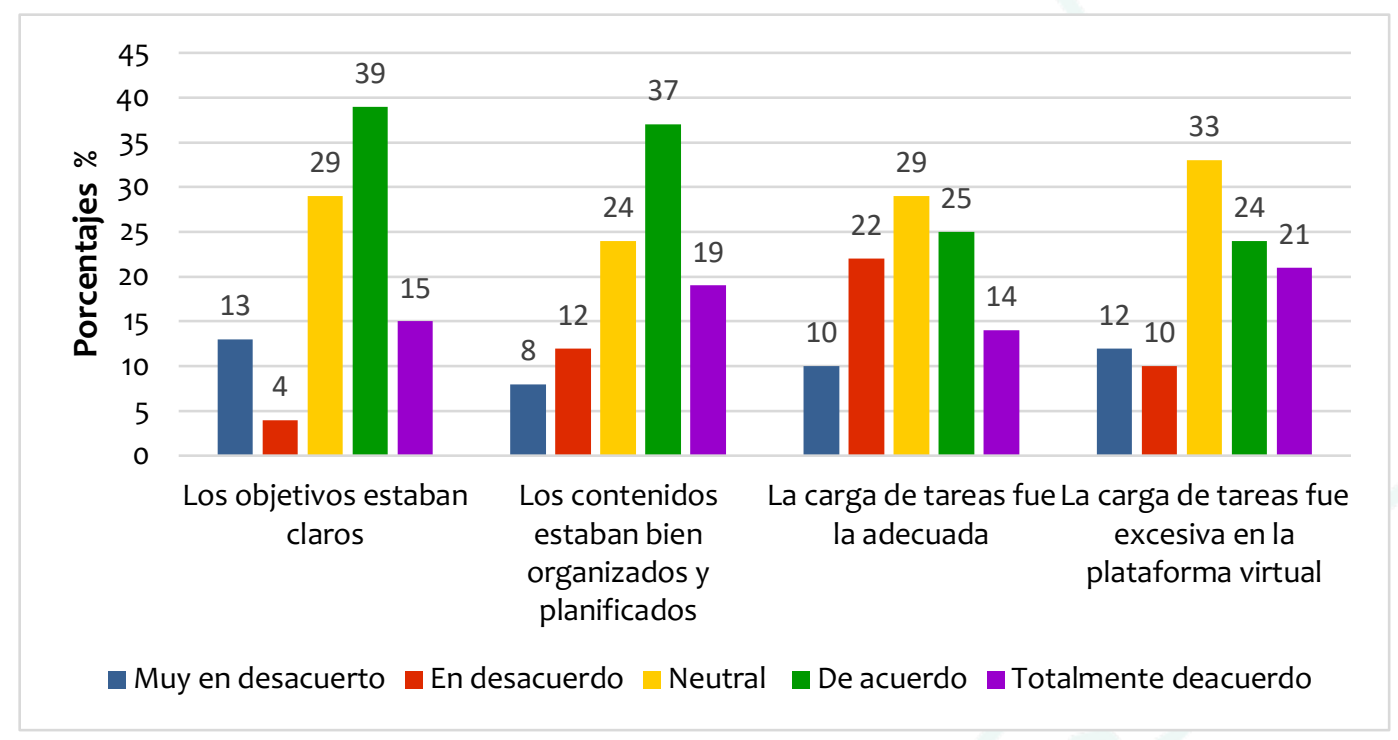

Fuente: Elaboración propia

En cuanto a los recursos y herramientas digitales más utilizados, se preguntó a los estudiantes cuáles han sido las herramientas y recursos de trabajo que más utilizan para el desarrollo de las actividades y clases virtuales, en primer lugar mencionaron que han estado usando Chats a través de WhatsApp, video clase a través de la plataforma de Google Meet, Zoom y otros recursos como sitios académicos y páginas web recomendadas por sus profesores, libros de texto y bibliotecas virtuales, aplicaciones como Messenger, destacando el uso de la Plataforma del Sistema Universidad Virtual, Google Classroom.

Referente a las plataformas virtuales, la frecuencia con la que los estudiantes dijeron estarlas utilizando, un 39 \% las usaron siempre, un $19 \%$ casi siempre, mientras que un 22 \% frecuentemente, el $14 \%$ afirmaron que rara vez y un $6 \%$ nunca las utilizó.

Con respecto a la frecuencia del uso de redes sociales para sus actividades académicas, un $26 \%$ dijo usarlas siempre, mientras que $22 \%$ casi siempre, un $20 \%$ las utilizó frecuentemente, un 17 \% rara vez, mientras que el 15 \% nunca utilizó las redes sociales para sus actividades académicas.

La frecuencia del uso del correo electrónico, un 38 \% siempre lo utilizó, un $10 \%$ casi siempre, un $23 \%$ frecuentemente, mientras que un 18 \% rara vez y un $11 \%$ nunca lo usó. 


\subsection{Análisis cualitativo}

Análisis de los resultados a parir de los talleres virtuales, los cuales fueron programados por temáticas que a continuación se describen; el primer tema que se abordó fue "vivencia personal durante la contingencia y confinamiento", los estudiantes expresaron el grado de vulnerabilidad en el que se encontraban en ese momento, han expresado su gran dolor y preocupación por la pérdida de familiares y amigos, vecinos y compañeros de estudio, esta pérdida de familiares cercanos han mermado la salud física y emocional así como la capacidad de resiliencia ante el fenómeno que se está viviendo sobre la pandemia provocada por el Covid-19, los estudiantes han comentado que estos acontecimientos ha traído como consecuencias el desinterés y descuido a sus tareas escolares, comentaron que han priorizando otras actividades como el cuidado de los adultos mayores, la conservación o búsqueda de empleo, argumentaron que han perdido sus propios empleos así como la pérdida de empleo de sus propios padres, la pérdida de empleo ha repercutido en el poder adquisitivo de bienes y servicios, impactando directamente en la adquisición de una red de internet inalámbrico y equipo de cómputo tan necesario para realizar sus actividades académicas escolares.

La falta de dispositivos electrónicos como una computadora o un celular inteligente para realizar sus tareas escolares, el uso de internet en casa se ha visto comprometido debido a la desfavorable situación económica que está viviendo la familia de este grupo de estudiantes bajo estudio, el cierre de pequeños negocios prestadores de servicios, centros comerciales, empresas y el comercio informal eran espacios donde solían laborar los padres y los propios estudiantes; impactando su frágil economía y en consecuencia, los conflictos familiares no se hicieron esperar, este fenómeno ha sido recurrente durante toda la investigación, puesto que, un significativo número de estudiantes dejó de asistir a las sesiones virtuales, algunos otros, su acceso fue intermitente, a la pregunta expresa sobre las causas de la baja asistencia, los participantes argumentaron que existían “conflictos y diferencias entre sus tutores y ellos", en este contexto, se documentó que estos conflictos entre la familia, eran por cuestiones económicas, los estudiantes tienen 
que vivir en un ambiente estresante, poco armoniosos y espacios reducidos cuya consecuencia ha sido el bajo rendimiento escolar.

Como se observa en los resultados, la vivencia y convivencia durante la contingencia no ha sido fácil para nadie, mucho menos para los estudiantes que muchos de éstos son adolescentes.

Por otra parte, se preguntó a los estudiantes si contaban con equipo de cómputo portátil o fijo en casa para realizar sus actividades, un 30 \% contestó que no contaban con equipo de cómputo en casa, comentaron que antes de la pandemia, realizaban sus actividades académicas en el centro de cómputo que se localiza en la biblioteca central de su escuela o en su defecto hacían uso de los centros de cómputo que se localizan en los alrededores de la institución donde estudian, esto, con un bajo costo por su uso, sin embargo, éstos fueron cerrados debido a la pandemia y el confinamiento, en consecuencia, no tienen donde realizar sus actividades escolares.

Otra de las inquietudes personales de los estudiantes, consistió en la falta de comprensión sobre el trabajo académico, actividades y tareas escolares que fueron solicitados por los docentes, argumentaron que las indicaciones al momento que el docente solicitaba las actividades, las instrucciones no siempre han sido claras, un $40 \%$ consideró que las instrucciones no fueron explicadas claramente por el docente o que no la entendieron, motivo por el cual decidían no realizarla o la copiaban a otro compañero dando como resultado un nulo aprendizaje, el $6 \%$ comentaron sobre el exceso de tareas que se acumularon con otras actividades a realizar, se les preguntó sobre las estrategias de aprendizaje que estaban utilizando a lo que comentaron que dieron prioridad a las asignaturas que entendían más o que tenían un buen acompañamiento por parte del docente, dejando de lado las asignaturas complicadas o poco importantes, de acuerdo al criterio de cada estudiante; mientras que el 8 \% mencionó que no tuvo ninguna limitante para realizar sus actividades académicas.

En cuanto al rendimiento escolar, un $16 \%$ de los estudiantes afirman que, uno de los factores ha sido la pericia del profesor en el manejo de la plataforma, dado la falta de orden en los contenidos que subieron a la plataforma de Google Classroom; consideraron que los docentes no poseían las competencias digitales necesarias, no estaban preparados ni 
capacitados para el manejo de plataformas virtuales, en consecuencia las clases remotas fue todo un reto para algunos docentes (Figura 5).

Figura 5 - Limitantes para realizar las actividades de las asignaturas

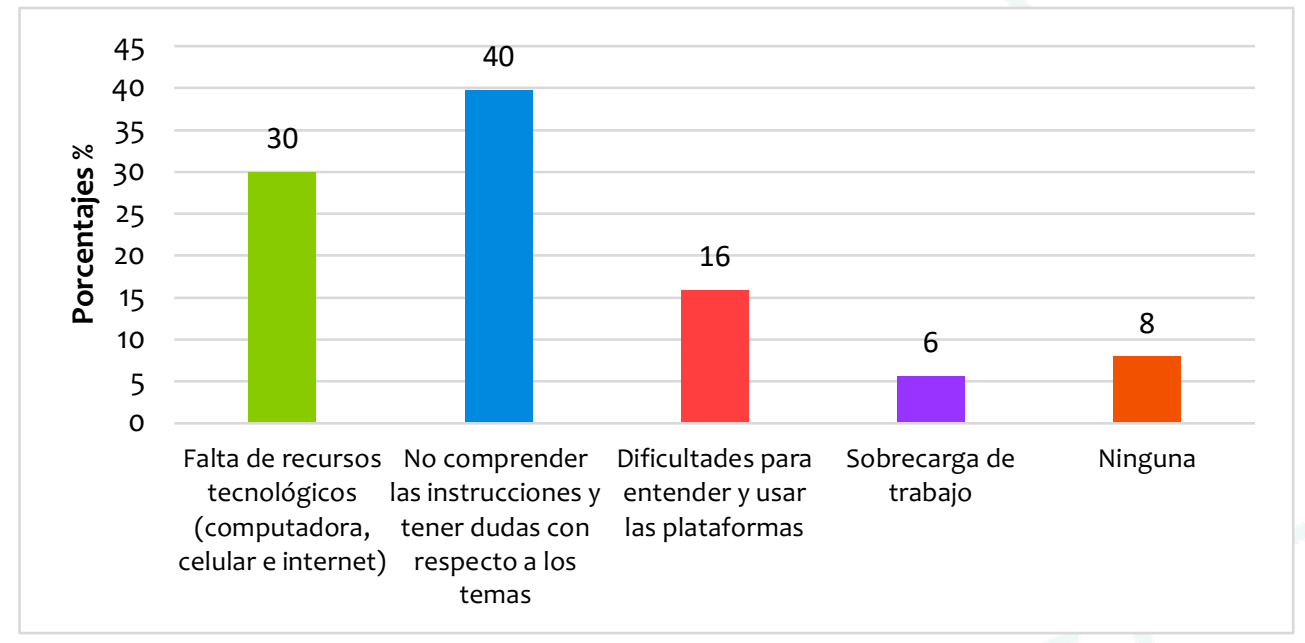

Fuente: Elaboración propia

El segundo tema abordado fue "Mis sentimientos el confinamiento y la contingencia". Se preguntó a los estudiantes si habían experimentado algún episodio de Ilanto, desesperanza, sentimientos de tristeza, soledad o culpa durante su confinamiento, a lo que expresaron que repentinamente han experimentado ataques de ira, enojo, frustración y desde luego llanto, sobre todo cuando las cosas no van bien en casa y en la escuela por las expectativas no cumplidas, han comentado que se han refugiado en sí mismos, otros compartieron sus sentimientos con amigos y compañeros que están transitando por la misma situación, aseveraron que estos temas no son abordados con las personas adultas con las que viven, debido a que, no se les permite expresar estos sentimientos frente a familiares, o frente a sus propios padres, ellos mismos mencionan sentirse incomprendidos, poco valorados por sus propios padres y maestros, han comentado que su mal comportamiento y desacuerdos de algunos, su rebeldía, su mal estado de ánimo y su irritabilidad, es debido a que no pueden expresarse abiertamente con la familia, lo que los ha orillado a buscar a otras personas o distintas soluciones ante sus problemas.

Sin duda que, dentro de los impactos directos que la pandemia ha dejado a este grupo bajo estudio, ha sido ansiedad, depresión, estrés y un conjunto de sentimientos encontrados con los que estos jóvenes deben lidiar; por un lado, el confinamiento y toda la 
problemática que conlleva, la posibilidad latente de un posible contagio de la familia, por otro lado, la carga de actividades escolares, las clases virtuales, sus relaciones intrafamiliares deterioradas y algunos casos fracturadas por el largo periodo de convivencia, la frágil economía en la que viven las familias, sin duda es un detonador importante que ha afectado significativamente el estado de ánimo, la productividad y el desempeño académico de los estudiantes.

La depresión, la fatiga y ansiedad, fueron sentimientos que se registraron como una constante en los estudiantes de sexto semestre, éstos manifestaron que, el hecho de estar cursando el último semestre de preparatoria se les había incrementado las actividades escolares, la presión escolar que tuvieron que vivir en los últimos meses de confinamiento, los ha agotado de manera significativa.

El confinamiento; la falta de convivencia entre los propios estudiantes, una inesperada despedida presencial con sus compañeros de curso y sus profesores, ha generado depresión, nostalgia y cierta angustia en los estudiantes, aunado a lo anterior, la clausura de fin de curso que no se llevó a cabo de forma presencial, donde no tuvieron oportunidad de despedirse personalmente, comentaron, que estos eventos les ha provocado frustración y por ende, una gran depresión que los ha llevado, a algunos de éstos, al consumo de antidepresivos y al consumo de bebidas alcohólicas.

Otro fuerte impacto que se documentó fue la pérdida de algunos familiares cercanos como la Mamá o el Papá, los abuelos, hermanos, amigos o vecinos que fueron afectados por la pandemia y que habrían enfermado y fallecido debido al contagio por Covid-19, aunado a su corta edad e inexperiencia para afrontar estos trágicos sucesos, el cambio radical que ha provocado la pandemia a su vida, desencadenó en ellos una serie de conflictos emocionales suficientemente fuertes que requieren de una especial atención.

Han comentado que, estar en casa, tener una constante convivencia con sus familiares, ha desencadenado desavenencias entre los adolescentes y adultos, se documentaron abusos constantes de los padres hacia los jóvenes, de el Papá hacia la Mamá, hermanos mayores abusivos, afectando tanto al género femenino como al masculino, en una menor escala; se registraron y documentaron embarazos no planeados de estudiantes de sexto semestre lo que ha complicado aún más su desempeño en la escuela y en muchos de los casos los estudiantes han decidido abandonar la escuela. 
Finalmente, se abordó el tema, "Vivir mi nueva realidad", fue importante conocer sobre lo que piensan, cómo están viviendo esta nueva realidad que se ha presentado a partir de la contingencia y el confinamiento, se les preguntó si han comprendido sobre la importancia de las enseñanzas que ha traído a su vida la pandemia, los estudiantes han considerado que sin duda ha cambiado su vida de manera radical ya que para ellos ha sido una situación muy fuerte el cambio de rutina en su vida, muchos de ellos afirmaron que ha sido un cambio negativo en todas sus formas, consideraron que se les ha quitado su libertad, acostumbrados a pasar mucho tiempo en los centros educativos, donde sus compañeros de clase es todo para ellos, afirmaron que el confinamiento les ha caído mal, existen cosas que aun no entienden como lo es la pérdida de un ser querido, por lo que tendrán que trabajar estos sentimientos y emociones con algún especialista para volver a sentirse seguros consigo mismos, comentaron sentirse sensibles y afectados, no saben si se adaptarán a la nueva realidad, aseguraron sentirse tristes, confundidos y desorientados, sin un propósito u objetivo claro o bien definido.

Estos jóvenes, han desarrollado sentimientos de enojo, frustración y poca tolerancia con las personas que están a su alrededor, se observó este fenómeno en la forma de relacionarse con los demás durante las dinámicas que se realizaron en los talleres, en el intercambio de ideas, en la forma de expresarse y dirigirse ante los demás, se observó incluso timidez y poca facilidad para expresar sus sentimientos.

Se consideró relevante conocer las experiencias de los estudiantes sobre el trabajo educativo bajo la modalidad virtual, donde realizaron sus actividades escolares desde casa, a esta pregunta un 33 \% consideró que ha sido una excelente experiencia, para el 34 \% ha sido una buena experiencia, un $29 \%$ la consideraron regular y para un $4 \%$ las actividades escolares realizadas desde casa, ha sido una mala experiencia (Figura 6). 
Figura 6 - Experiencias sobre las clases virtuales.

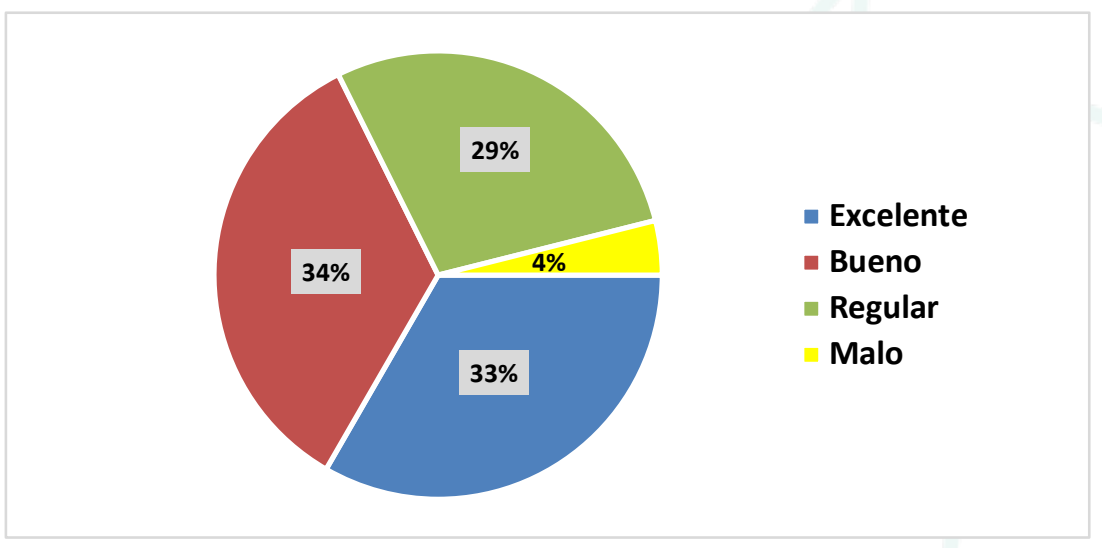

Fuente: Elaboración propia

\section{DISCUSIÓN}

La presente investigación ha permitido identificar las principales problemáticas, afectaciones e impactos que han tenido los estudiantes en su vida cotidiana causados por la actual pandemia del Covid-19. Los resultados mostraron un alto grado de vulnerabilidad debido a los acontecimientos provocado por la contingencia sanitaria y el confinamiento, la desfavorable situación socioeconómica en la que viven los propios estudiantes y sus familias, con la pandemia se volvió crítica, la pérdida de empleos tanto de los padres de familia como de los propios estudiantes, quienes también, laboraban para mantenerse y ayudar en el gasto familiar.

Al igual que en este estudio, Cervantes et al. (2020), mencionan que los estudiantes, y la población en general, se enfrentan a los efectos del Covid-19 en la vida cotidiana, como el cierre de escuelas, empresas y lugares públicos, cambios en las rutinas de trabajo y la organización familiar.

Estudios como el de Ornell et al. (2020), han documentado que, además de enfrentarse al miedo por la muerte de familiares cercanos, el aislamiento conlleva sentimientos de impotencia y abandono, que se suman a las manifestaciones del "burnout" -fatiga física y mental, dolores de cabeza, insomnio, irritabilidad, frustración, problemas gastrointestinales y cardiacos- (RODRÍGUEZ et al., 2017 p. 48), los estudiantes deben enfrentar los impactos financieros derivado de la pérdida total o parcial de sus empleos o de los propios padres. Al respecto Gudi y Tiwari (2020) han analizado los efectos del Covid- 
19 en la vida cotidiana, considerando la importancia en el cuidado de la salud, empleo, educación, alimentación y los impactos que conlleva la falta de éstos.

El tránsito de la enseñanza presencial a la virtual, ha traído consigo un importante impacto pedagógico en términos de calidad y equidad en todo el sector educativo; como lo menciona Francesc (2020), universalmente, el paso a la educación a distancia, lejos de ser una solución planificada previamente, ha sido, en realidad, la única solución de emergencia para intentar garantizar la continuidad pedagógica, por lo tanto, es necesario una nueva visión y un cambio metodológico para responder a las necesidades pedagógicas que ofrece este nuevo reto de la enseñanza a distancia.

De acuerdo con la UNESCO-IESALC (2020), el cierre de las escuelas ha tenido repercusiones en el proceso de aprendizaje, aunque también en el bienestar psicológico y socioemocional de los estudiantes, padres y docentes. Los estudiantes que no disponen de la tecnología y de la infraestructura necesaria para el aprendizaje a distancia, han tenido dificultades para garantizar su continuidad pedagógica durante este período de pandemia.

Los resultados que aquí se exponen, evidencian que el cese temporal de las actividades escolares presenciales, particularmente a los estudiantes de sexto semestre quienes estaban por finalizar la preparatoria, aspiraban a ingresar a la educación superior una vez graduados de la educación preparatoria, sin embargo, debido a la contingencia provocada por el Covid-19, muchos han cambiado sus planes priorizando sus necesidades, esta situación sin precedentes tiene consecuencias en cascada en la vida de los estudiantes (UNESCO-IESALC, 2020) impactando su forma y calidad de vida.

Sin una idea clara de cuánto tiempo durarán los impactos inmediatos sobre su vida cotidiana, los costos económicos, impactos a su salud física y emocional, por ende, la continuidad de sus aprendizajes, ha traído fuertes repercusiones en la estabilidad socioemocional de estos jóvenes. Las necesidades y dificultades que han enfrentado son diversas, desde el acceso a recursos tecnológicos, baja conectividad con las clases virtuales, escasa disposición de un equipo de cómputo para desarrollar sus actividades escolares han mermado su desempeño académico y emocional, de acuerdo con Gervacio y Castillo (2020) no todas las familias poseen acceso a internet estable que permita la conexión de los miembros de la familia, considerando que muchas de éstas, cuentan con varios hijos en etapa escolar, lo que representa una dificultad más grande tener que compartir los 
dispositivos informáticos entre ellos, además, tener que apoyar las diferentes actividades solicitadas en la escuela y atender las necesidades de la familia.

A corto, mediano y largo plazo, las universidades y autoridades educativas deben diseñar estrategias para reducir la brecha tecnológica, ésta sea más accesible y se ponga al servicio de estudiantes y profesores que no tienen acceso a la red o que no cuentan con dispositivos digitales en casa, reciban de alguna manera apoyo institucional para cubrir estas carencias (SÁNCHEZ et al., 2020).

El análisis de los resultados permitió observar baja accesibilidad cognitiva en entornos virtuales, los estudiantes consideraron que no ha sido fácil usarlos y entenderlos, además de las dificultades que ha representado comprender las instrucciones que dan los docentes al momento que solicitan una tarea o actividad en las distintas plataformas digitales; estudios como el de Onrubia (2016), sugiere que los entornos educativos online o virtuales debieran facilitar procesos de aprendizaje basados en la actividad y construcción del conocimiento, sobre el mismo tema, Cabero et al. (2006) afirman que los entornos virtuales son algo más que la mera recepción de contenidos o información, implica que dichos entornos se organicen y demanden a los estudiantes la complementación de tareas o actividades de diversa naturaleza, por lo tanto, los entornos de aprendizaje virtual deben ser escenarios de comunicación e interacción social, ricos, variados y en permanente interacción entre los estudiantes y el docente (SUÁREZ y GROS, 2013), lo que claramente no ha sido posible con los estudiantes bajo estudio.

Por otro lado, para estos estudiantes, la búsqueda y navegación a través de páginas web, la instalación y uso de aplicaciones, ha resultado complicado debido a sus escasas competencias digitales en el uso efectivo de los recursos tecnológicos. Por lo anterior, los espacios virtuales deben considerarse como un apoyo, un recurso para el diseño de estrategias pedagógicas, un catalizador de la innovación pedagógica de la docencia.

Es pertinente una planificación cuidadosa para el aprendizaje en línea, que atienda el apoyo de diferentes tipos de interacciones tan importantes para el proceso de aprendizaje (HODGES et al., 2020). El aprendizaje virtual debe reconocerse como un proceso social cognitivo, no simplemente como una cuestión de transmisión de información, la falta de claridad en las instrucciones que dan los profesores al solicitar las tareas escolares ha representado una dificultad importante en el desarrollo del proceso de 
enseñanza aprendizaje, complicando aún más la precaria situación socioemocional de los estudiantes en la entrega de actividades y tareas solicitadas, impactando en sus calificaciones, de acuerdo con Lau et al. (2015) las indicaciones o instrucciones deben considerarse como estrategias metodológicas de enseñanza, las estrategias instruccionales son consideradas como acciones que los docentes deben crear durante el proceso de enseñanza-aprendizaje para que la construcción de conocimiento y el desarrollo de habilidades sean las óptimas en la formación de los estudiantes.

En este contexto, quedó la evidencia que los docentes no dimensionaron la problemática a la que se estaban enfrentando e hicieron uso de sus escasos recursos y competencias tecnológicas disponibles para diseñar sus cursos como si se continuara en situación de aula presencial, evidentemente los resultados no han sido favorecedores, lo que ha representado un importante reto el transformar las clases presenciales a modo virtual, lo que requiere de un cambio al currículum en la metodología pedagógica, transformándola en una estrategia de enseñanza multimodal (presencial/virtual); al respecto, la UNICEF (2020) ha recomendado a los docentes que brinden a los estudiantes indicaciones claras y sencillas, jerarquizadas según su relevancia, así mismo, recomienda indicar el orden de las actividades a desarrollar y procurar que las instrucciones de las actividades estén detalladas paso a paso, recordando que no se está con los estudiantes para resolver sus dudas al momento; las instrucciones son determinantes para que los docentes creen procesos de enseñanza-aprendizaje en la construcción de conocimiento y el desarrollo de habilidades sean las óptimas para la formación de los estudiantes (LAU et al., 2015).

Es necesario revisar si las actividades que se proponen son dinámicas, lúdicas, de interés y uso para el estudiante, priorizando competencias transversales en el currículum, abordando temas emergentes, como lo proponen Bedolla et al. (2019); al respecto, la UNICEF (2020), recomienda que para el diseño de actividades de aprendizaje se debe considerar la variabilidad y nivel de competencia curricular de los estudiantes, observar y determinar el nivel de competencia de cada uno de los estudiantes y determinar las áreas que requieren apoyo, tener en cuenta diferentes grados de realización y complejidad (demanda cognitiva) en las actividades planteadas. 
Los impactos que han tenido los estudiantes han sido diversos, dentro de los cuales se encuentran la falta de recursos tecnológicos para realizar sus actividades en línea, no contar con un equipo de cómputo, internet, celulares con un sistema de alta gama, falta de recursos económicos para su adquisición, no contar con recursos económicos para el pago de internet, no ha sido fácil para estos estudiantes accesar a las plataformas virtuales, o para conectarse y recibir la instrucción de forma virtual; de acuerdo con Francesc (2020) en América Latina, solo el 52 \% de los hogares cuenta con equipamiento tecnológico y conectividad de banda ancha, este fenómeno ha dificultado la transición hacia la educación a distancia, México y especialmente en el estado de Guerrero, se ha visto reflejada esta problemática en los estudiantes de todos los niveles educativos.

La emergencia provocada por la pandemia, se ha acompañado de otros impactos no menos importantes, en ámbitos como el socioemocional, el laboral, el financiero. La vida cotidiana y la convivencia familiar ha sufrido cambios importantes y un desequilibrio emocional (GERVACIO y CASTILLO, 2020), los estudiantes han tenido que reorganizar su vida cotidiana para ajustarse a una situación de confinamiento; de acuerdo con la UNESCOIESALC (2020), la pérdida de contacto social y de las rutinas de socialización que forman parte de la experiencia cotidiana de un estudiante de educación media superior tendrán un alto costo en todos los ámbitos.

El aislamiento que va inevitablemente asociado al confinamiento tendrá efectos en términos de equilibrio socioemocional que dejarán huella, en particular, en aquellos estudiantes con problemáticas ya existentes, ya que la efectividad de la enseñanza y el aprendizaje dependen de que las actividades educativas tengan fundamentos pedagógicos y que los profesores y estudiantes tengan un mínimo de estabilidad socioemocional (TYNG et al., 2017).

La recomendación de las autoridades del sector salud, quédate en casa, fue considerada como una estrategia de prevención para salvaguardar la vida de las personas e intentar disminuir la posibilidad de contagios, implicando para el sector educativo, desplegar acciones conducentes a continuar con el ciclo escolar vigente, con tensiones, dificultades y retos para todos los involucrados en la atención de la contingencia. 


\section{CONCLUSIONES}

México al igual que otros países, durante la pandemia de la COVID-19, las escuelas están ofreciendo enseñanza a distancia a través de aulas virtuales, las universidades del país y del mundo, tuvieron que sucumbir ante el movimiento online que fue considerada como una de las alternativas más viables para continuar y finalizar el segundo periodo del semestre febrero-julio del 2020, si bien es cierto que este suceso trajo consigo tensión, ansiedad y diferencias de opiniones, era claro que el gobierno Mexicano al igual que otros gobiernos del mundo, las instituciones educativas, docentes, personal administrativo y estudiantes no estaban preparados para hacer frente a la contingencia y al confinamiento.

Por otro lado, considerando que docentes y estudiantes ya contaban con alguna experiencia y capacitación previa con la enseñanza en línea, bajo la emergencia actual, que tomó de sorpresa a todos, fue complicado diseñar una adecuada planeación didácticopedagógica emergente con características de clases virtuales y a distancia, por lo que, el sistema educativo mexicano en general, tuvo que improvisar e implementar estrategias emergentes, asi como enfrentar diversos retos educativos.

El tránsito de la enseñanza presencial a la virtual, ha traído consigo un importante impacto pedagógico en términos de calidad y equidad en todo el sector educativo y en particular a los estudiantes bajo estudio; afectando negativamente los resultados de la enseñanza aprendizaje, el desarrollo socioemocional y conductual, además de un alto índice de deserción. Como lo señala la UNESCO, las repercusiones no solo han sido sobre el proceso de aprendizaje, sino que se ha visto afectado tanto el bienestar psicológico y emocional de los estudiantes, padres y docentes.

El traslado a la educación virtual, lejos de ser una solución planificada previamente, ha sido, en realidad, la única solución de emergencia para intentar garantizar la continuidad pedagógica, aunque ésta es una opción para algunos, este estudio demostró que está fuera del alcance para muchos estudiantes de diferentes niveles educativos. La falta de acceso a computadoras y a Internet en el hogar, así como el bajo nivel de conocimientos informáticos, ha puesto en desventaja a muchos estudiantes. Este estudio demostró que el éxito del aprendizaje virtual también depende de los conocimientos informáticos de los 
docentes y de los padres, así como la estabilidad socioemocional tanto del docente como del estudiante, para una efectiva enseñanza - aprendizaje.

El abordaje de las diversas problemáticas provocadas por la pandemia requiere de un trabajo profundo, desafiante y continuo, se requiere del diseño de estrategias prácticas emergentes e inmediatas, la escuela como institución y como agente transformador de las prácticas educativas, pedagógicas, debe diseñar estrategias que garantice una educación flexible, inclusiva, equitativa y de calidad; una educación que responda a las necesidades, problemáticas y retos como respuesta a la presente pandemia del Covid-19.

El docente como facilitador y promotor de los aprendizajes, el estudiante y su aprendizaje como el centro del proceso educativo, padres de familia, y sociedad en general, deben involucrarse en el diseño de nuevos procesos socioeducativos que respondan a las necesidades y retos actuales generados por la actual pandemia del Covid-19.

Finalmente, para construir sociedades más inclusivas y sostenibles, la educación debe estar orientada a fomentar el respeto a los derechos humanos y a la biodiversidad, debe fomentar habilidades de pensamiento crítico, impartir competencias digitales, habilidades para la vida y conocimientos científicos que son esenciales para tomar decisiones informadas y fomentar una ciudadanía responsable, particularmente importante en un momento en que la pandemia del COVID-19 ha afectado al sector educativo de manera global, lo que pone al descubierto las desigualdades generalizadas que requieren intervención y recursos urgentes e inmediatos para cumplir con los derechos de todos a la educación.

Los resultados de esta investigación respaldan la tesis que la educación y el aprendizaje deben ser considerados como una prioridad social que requiere repensarse y replantearse con nuevas estrategias ante la crisis provocada por la pandemia del coronavirus COVID-19.

Los responsables de la formulación de políticas educativas en los planos local, regional y nacional deberan integrar la Educación para un Desarrollo Sostenible en las políticas de educación, incluidas las que se refieren a los entornos de aprendizaje, los planes de estudios, la formación de docentes para fortalecer sistemáticamente las relaciones de sinergia entre la educación y el aprendizaje formal, no formal e informal. 
Revista do Programa de Pós-Graduação em Educação da Unochapecó

ISSN 1984-1566 (on-line) ISSN 1415-8175 (impressa)

\section{REFERENCIAS}

ALZATE Yepes, T.; PUERTA C., A. M. \& MORALES, R. M. Una mediación pedagógica en educación superior en salud. El diario de campo. Revista Iberoamericana De Educación, v. 47, n. 4, p. 1-10, 2008. DOI: https://doi.org/10.35362/rie4742301

ARIAS, O., E.; EUSEBIO, J.; PÉREZ A., M.; VÁSQUEZ, M. y ZOIDO, P. Del papel a la nube: Cómo guiar la transformación digital de los Sistemas de Información y Gestión Educativa (SIGED), 2019. DOI: http://dx.doi.org/10.18235/0001749

BEDOLLA, S, R.; CASTILLO, E. B.; BEDOLLA, S, J.; GERVACIO, J. H. Educación Ambiental como tema transversal en el plan, programa y la secuencia didáctica en tres programas educativos de la Universidad Autónoma de Guerrero. Revista Pedagógica, Chapecó, v. 21, p. 292-305, 2019. DOI: https://doi.org/10.22196/rp.v21io.4761

CABERO, J.; MORALES, J. A.; ROMERO, R.; BARROSO, J.; CASTAÑO, C.; ROMÁN, P.; LLORENTE, Ma. del C.; P. PRENDES, M.; CEBRIÁN, M.; PÉREZ, A.; BALLESTERO, C.; MARTÍNEZ, F.; PÍO, Á.; GISBERT, M. \& SALINAS, J. Formación del profesorado universitario en estrategias metodológicas para la incorporación del aprendizaje. Pixel-Bit. Revista de Medios y Educación, n. 27, p. 11-29, 2006. Disponible en https://www.redalyc.org/pdf/368/36802702.pdf Acceso en: 22 noviembre 2020.

CERVANTES, H., E., \& GUTIÉRREZ, S., P. R. Resistir la Covid-19. Intersecciones en la Educación de Ciudad Juárez, México. Revista Internacional De Educación Para La Justicia Social, v. 9, n. 3, p. 7-23, 2020. DOI: https://doi.org/10.15366/riejs2020.9.3.001

DIARIO OFICIAL DE LA FEDERACIÓN. Acuerdo por el que se suspenden las clases en las escuelas de educación preescolar, primaria, secundaria, normal y demás para la formación de maestros de educación básica del Sistema Educativo Nacional, así como aquellas de los tipos medio superior y superior dependientes de la Secretaría de Educación Pública, 2020. (DOF número 02/03/20). Disponible en https://www.dof.gob.mx/nota_detalle.php?codigo=5589479\&fecha=16/03/2020. Acceso en: 8 de septiembre de 2020.

FRANCESC, P. COVID-19 y educación superior en américa latina y el caribe: efectos, impactos y recomendaciones políticas. Informe: Análisis Carolina, 2020. Disponible en https://www.fundacioncarolina.es/wp-content/uploads/2020/06/AC-36.-2020.pdf Acceso en: 17 de mayo de 2020.

GERVACIO J. H. y B. CASTILLO E. Desafíos educativos que enfrenta el Colegio Nacional de Educación Profesional Técnica ante la pandemia sanitaria Covid-19. Revista del Centro de Investigación de la Universidad La Salle v. 14, n. 53, p. 45-66, 2020. DOI: https://doi.org/10.26457/recein.v14i53.2658

GÓMEZ, B. S. Metodología de la investigación. Red Tercer Milenio S.C. Tlalnepantla, Estado de

México,

2012.

Disponible

en 
Revista do Programa de Pós-Graduação em Educação da Unochapecó

ISSN 1984-1566 (on-line) ISSN 1415-8175 (impressa)

http://www.aliat.org.mx/BibliotecasDigitales/Axiologicas/Metodologia_de la investigacio n.pdf. Acceso en: 15 de marzo de 2020.

GUDI, S. K. y TIWARI, K. K. Preparedness and lessons learned from the novel coronavirus disease. International Journal of Occupational and Environmental Medicine, v. 11, n. 2, p. 108-112, 2020. DOI: https://doi.org/10.34172/ijoem.2020.1977

HERNÁNDEZ-SAMPIERI, R., FERNÁNDEZ, C. C. y BAPTISTA, L.P. Metodología de la Investigación. Sexta Edición. Editorial Mc. Graw Hill, 2018.

HODGES, Ch. B.; S., MOORE, B., B. LOCKEE, T., TRUST \& M., A. BOND. The Difference Between Emergency Remote Teaching and Online Learning, 2020. Disponible en https://er.educause.edu/articles/2020/3/the-difference-between-emergency-remote-teaching-andonline-learning Acceso en: 13 de junio de 2020.

LAU, J.; J. CORTÉS; M. Á. MARZAL; J. TARANGO; J. PIRELA; A. TIRADO; A. GÁRATE y C. OSUNA. Demanda y competencias informativas de académicos (DECIA). Una caracterización internacional. Proyecto de investigación. Universidad Veracruzana. Instituto de Ingeniería- Región Veracruz/Dirección General de Desarrollo, 2015. Disponible en http://www.jesuslau.com.mx/decia/protocolo/descarga.php Acceso en: 28 de marzo de 2020.

MENDIOLA, S. M.; M. P. M. HERNÁNDEZ; R. T. CARRASCO; M. A. SERVÍN; A. K. HERNÁNDEZ R.; C. A. JAIMES V.; M. A. BENAVIDES L. y V. J. RENDÓN C. Retos educativos durante la pandemia de covid-19: una encuesta a profesores de la UNAM. Revista Digital Universitaria, p, 1-23, 2020. https://www.revista.unam.mx/wp-content/uploads/AOP.pdf

MONJE, Á. C. A. Metodología de la Investigación Cuantitativa y Cualitativa. Guía didáctica. Colombia, 2011. https://www.uv.mx/rmipe/files/2017/02/Guia-didactica-metodologia-de-lainvestigacion.pdf

ONRUBIA, J. Aprender y enseñar en entornos virtuales: Actividad conjunta, ayuda pedagógica y construcción del conocimiento. RED. Revista de Educación a Distancia. V. 50, n. 3, p. 1-14, 2016. DOI: http://dx.doi.org/10.6018/red/50/3

OMS. Considerations for school-related public health measures in the context of COVID19. Annex to Considerations in adjusting public health and social measures in the context of COVID-19, 2020. Disponible en https://www.who.int/publications/i/item/considerationsfor-school-related-public-health-measures-in-the-context-of-covid-19. Acceso en: 25 de septiembre de 2020.

ORNELL, F., SCHUCH, J. B., SORDI, A. O. y KESSLER, F. H. Pandemic fear and Covid-19: Mental health burden and strategies. Brazilian Journal of Psychiatry, n. 8, p. 232-235, 2020. DOI: https://doi.org/10.1590/1516-4446-2020-0008 
Revista do Programa de Pós-Graduação em Educação da Unochapecó

ISSN 1984-1566 (on-line) ISSN 1415-8175 (impressa)

PÉRTIGAS, D. S. y PITA, F. S. Determinación del tamaño muestral para calcular la significación del coeficiente de correlación lineal. Unidad de Epidemiología Clínica y Bioestadística. Complexo Hospitalario Juan Canalejo. A Coruña. Cuadernos de Atención Primaria. v. 9, n. 4, p. 209-211, 2002.

PITA, F. S. Determinación del tamaño muestral. Unidad de Epidemiología Clínica y Bioestadística. Complexo Hospitalario Juan Canalejo. A Coruña. Cuadernos de Atención $\begin{array}{lllll}\text { Primaria } & \text { n. } & 3, & \text { p. } & 138-141,\end{array}$ http://www.fisterra.com/mbe/investiga/gmuestras/9muestras.asp

RODRÍGUEZ, J. A., GUEVARA, A. y VIRAMONTES, E. Síndrome de burnout en docente. Revista de Investigación Educativa de la REDIECH. N. 14, p. 45-68, 2017. https://www.rediech.org/ojs/2017/index.php/ie_rie_rediech/article/view/39/22

SÁNCHEZ Mendiola, Melchor; MARTÍNEZ Hernández, Ana María del Pilar; TORRES Carrasco, Ruth; DE AGÜERO Servín, Mercedes; HERNÁNDEZ Romo, Alan K.; BENAVIDES Lara, Mario A.; JAIMES Vergara, Carlos A. y RENDÓN Cazales, Víctor J. Retos educativos durante la pandemia de COVID-19: una encuesta a profesores de la UNAM. Revista Digital Universitaria (RDU), p. 1-23, 2020. https://www.revista.unam.mx/wpcontent/uploads/AOP.pdf

SEP. Orientaciones pedagógicas para el inicio y organización del ciclo escolar 2020-2021. Guía para el trabajo docente. Secretaría de Educación Pública, 2020. Disponible en https://bibliospd.files.wordpress.com/2020/07/anexo-2-guczada-pedagc3b3gica-resumencte.pdf. Acceso en: 23 de septiembre de 2020.

SUÁREZ, C. y GROS, B. Aprender en red: de la interacción a la colaboración. Ed. UOC, 2013.

TAYLOR, S. J. y BOGDAN, R. Introducción a los métodos cualitativos de investigación. Ed. Paidós, 2000. http://mastor.cl/blog/wp-content/uploads/2011/12/Introduccion-a-metodoscualitativos-de-investigaci\%C3\%B3n-Taylor-y-Bogdan.-344-pags-pdf.pdf

TYNG Chai, M.; Amin HAFEEZ, U.; SAAD Mohamad, N. M. \& MALIK Aamir, S. The Influences of Emotion on Learning and Memory. Frontiers in Psychology, n. 8, p. 1454, 2017. DOI: https://doi.org/10.3389/fpsyg.2017.01454

UNICEF. Orientaciones para docentes y recursos digitales para atender a la diversidad en la educación a distancia en el contexto del COVID-19, 2020 ${ }^{\mathrm{a}}$. Disponible en https://www.unicef.org/peru/sites/unicef.org.peru/files/2020-

05/Orientaciones\%20\%26\%20recursos_MasInclusion\%2029.04.pdf. Acceso en: 23 de septiembre de 2020. 
Revista do Programa de Pós-Graduação em Educação da Unochapecó ISSN 1984-1566 (on-line) ISSN 1415-8175 (impressa)

UNESCO. La UNESCO ayuda a construir la nueva infraestructura de sistemas educativos resilientes a las crisis en los países del Pacífico., 2020. Disponible en https://es.unesco.org/news/unesco-ayuda-construir-nueva-infraestructura-sistemaseducativos-resilientes-crisis-paises-del. Acceso en: 8 de octubre de 2020.

UNESCO-IESALC. COVID-19 y educación superior: De los efectos inmediatos al día después: Análisis de impactos, respuestas políticas y recomendaciones. Informe técnico. Organización de las Naciones Unidas para la Educación, la Ciencia y la Cultura-Instituto Internacional para la Educación Superior en América Latina y el Caribe, 2020. Disponible en http://www.iesalc.unesco.org/wp-content/uploads/2020/05/COVID-19-ES-130520.pdf.

Acceso en: 6 de octubre de 2020.

YI, Y.; LAGNITON, P.; YE, S.; LI, E., \& XU, R. H. COVID-19: what has been learned and to be learned about the novel coronavirus disease. International journal of biological sciences, v. 16, n. 10, p. 1753-1766, 2020. DOI: https://doi.org/10.7150/ijbs.45134

Recebido em: 09-03-2021

Aprovado em: 07-05-2021

Publicado em: 24-05-2021 